\title{
ACELERAÇÃO DE PROCESSOS GEOMORFOLÓGICOS NAS VERTENTES DOS BAIRROS NOVA ITUIUTABA I E NOVA ITUIUTABA II - ITUIUTABA/MG
}

\author{
João Victor de Freitas Silva ${ }^{1}$ \\ Fernanda Luisa Ramalho ${ }^{2}$ \\ Tatiane Regina da Silva ${ }^{3}$ \\ Leda Correia Pedro Miyazaki ${ }^{4}$
}

\begin{abstract}
RESUMO: Atualmente, um assunto que vem ganhando destaque em debates e discussões de diferentes esferas da sociedade são as questões ambientais. Neste sentido, cientistas e pesquisadores buscam cada vez mais explicações e soluções para que se possa resolver ou minimizar os problemas ambientais, os quais afetam tanto o equilíbrio natural, quanto provocam impactos sobre a sociedade. Com o intuito de trazer contribuições para este debate, buscamos, por meio de pesquisas de campo e embasamento teórico, descrever a atual situação da expansão territorial urbana do município de Ituiutaba - MG, focando principalmente nos impactos causados pela aceleração dos processos geomorfológicos nas vertentes quando estas são ocupadas. $O$ objetivo principal desta pesquisa foi identificar a ocupação dos compartimentos do relevo, com ênfase para as vertentes, e caracterizar os principais impactos ambientais decorrentes da aceleração dos processos geomorfológicos nos loteamentos Nova Ituiutaba I e II do município. Como procedimentos metodológicos foram utilizados os seguintes: inicialmente foram feitos trabalhos de gabinete envolvendo levantamento histórico e bibliográfico da ocupação de Ituiutaba; foram feitos mapeamentos, esboços e perfis longitudinais do relevo e do solo e, por fim, realizou-se alguns trabalhos de campo na área estudada para identificar os principais impactos e avaliar se os mapeamentos estão representando os aspectos mapeados.
\end{abstract}

PALAVRAS-CHAVE: Problemas ambientais, expansão territorial, impactos ambientais.

ABSTRACT: Currently, an issue that has been gaining attention in debates and discussions from different walks of society are environmental issues. In this sense, scientists and researchers increasingly seek explanations and solutions so that you can resolve or minimize environmental problems, which affect both the natural balance, the cause impacts on society. In order to bring contributions to this debate, seek, through field research and theoretical basis, describe the current situation of urban territorial expansion of the city of Ituiutaba - MG, mainly focusing on the impacts of this process of territorial occupation. The main objective of this research was to identify the occupation of relief compartments, with emphasis on the slopes, and characterize the main environmental impacts on allotments New Ituiutaba I and II of the municipality. As methodological procedures we used the following: Initially were made cabinet work involving historical and literature occupation of Ituiutaba; mappings were done, sketches and longitudinal relief profile and the ground, and finally, field studies have been made in the area studied to identify main effects and assessing whether representing the mappings are mapped aspects.

\footnotetext{
${ }^{1}$ Graduando, Universidade Federal de Uberlândia - Campus Pontal. joaovictorfs14@yahoo.com

${ }^{2}$ Mestranda, Universidade Federal de Goiás - Campus Jataí. ramalho luisa@hotmail.com

${ }^{3}$ Graduanda, Universidade Federal de Uberlândia - Campus Pontal. tatiane_rs94@hotmail.com

${ }^{4}$ Docente, Universidade Federal de Uberlândia - Campus Pontal. lecpgeo@.ufu.br
} 
KEYWORDS: Environmental issues, territorial expansion, environmental impacts.

RESUMEN: En la actualidad, un problema que ha ido ganando la atención en los debates y discusiones de diferentes ámbitos de la sociedad son los temas ambientales. En este sentido, los científicos y los investigadores buscan cada vez más explicaciones y soluciones para que pueda resolver o minimizar los problemas ambientales, que afectan tanto el equilibrio natural, los impactos causan en la sociedad. Con el fin de aportar contribuciones a este debate, buscar, a través de la investigación de campo y la base teórica, describir la situación actual de la expansión territorial urbana de la ciudad de Ituiutaba - MG, centrándose principalmente en los impactos de este proceso de ocupación territorial. El principal objetivo de esta investigación fue identificar la ocupación de los compartimentos de socorro, con énfasis en las pistas, y caracterizar los principales impactos ambientales sobre las asignaciones Nueva Ituiutaba I y II del municipio. Como procedimientos metodológicos se utilizó la siguiente: ebanistería Inicialmente se hicieron implica ocupación histórica y la literatura de Ituiutaba; asignaciones se realizaron, bocetos y perfil longitudinal de alivio y el suelo, y por último, se han realizado estudios de campo en el área de estudio para identificar los efectos principales y la evaluación de si representa a las asignaciones se asignan aspectos.

PALABRAS CLAVE: Las cuestiones ambientales, la expansión territorial, los impactos ambientales.

\section{INTRODUÇÃO:}

A questão ambiental ganha, cada dia mais, espaço nas discussões mundiais, principalmente em relação aos debates sobre os impactos ambientais negativos, como por exemplo, o efeito estufa, as ilhas de calor, a ocupação em áreas de risco, os deslizamentos de encostas, os alagamentos em fundos de vale, os assoreamentos dos cursos d'água, feições erosivas entre outros. Neste sentido, cientistas e pesquisadores buscam cada vez mais explicações e soluções para que se possa resolver ou minimizar os problemas ambientais, os quais afetam tanto o equilíbrio natural, quanto provocam impactos sobre a sociedade.

Tais problemas são fortemente expressos no ambiente urbano, que, devido a sua dinâmica, é palco de diferentes impactos socioambientais que afetam o equilíbrio dinâmico natural, podendo, assim, ser facilmente identificados, pois, são impactos oriundos da degradação dos recursos naturais, da concentração populacional em locais ambientalmente inadequados, da falta de infraestrutura, de saneamento básico entre outros.

Atrelados a tais impactos ambientais, e ligados diretamente ao aumento populacional, o processo de urbanização, o qual ocorre geralmente em áreas 
periféricas, acontece muitas vezes de forma errônea e desordenada, sendo, frequentemente desprovidos de planejamento.

Diante da concentração populacional em áreas urbanas, as cidades "sem planejamento adequado" podem passar por um processo de expansão territorial urbana desordenado. Muitas vezes isso resulta em uma ocupação de compartimentos do relevo, sejam eles áreas de topo, fundos de vale ou vertentes, de forma inadequada, no qual, são incorporadas parcelas das áreas rurais para serem loteadas, podendo apresentar infraestrutura inadequada e/ou insuficiente.

As formas de ocupação das vertentes modificam e esculturam o relevo, manifestando-se na maioria das vezes em feições erosivas, cortes nas vertentes para terraplanagem, retirada da vegetação principalmente próxima aos cursos d'água, além da impermeabilização do comprimento de rampa das vertentes que aumenta o escoamento superficial. Todas essas intervenções contribuem para a degradação desse ambiente.

As cidades são os locais onde os impactos ambientais se manifestam de forma mais intensa, devido à grande transformação que a sociedade é capaz de promover na paisagem. Assim, optou-se em realizar uma investigação para analisar como essa ação antrópica está modificando e transformando as feições geomorfológicas da cidade de Ituiutaba/MG, com ênfase nos bairros Nova Ituiutaba I e Nova Ituiutaba II.

\section{Área de Estudo}

O município de Ituiutaba está localizado na porção oeste da Mesorregião do Triângulo Mineiro/Alto Paranaíba, especificamente na microrregião de Ituiutaba (Figura 01). 
Figura 01. Localização do município de Ituiutaba/MG
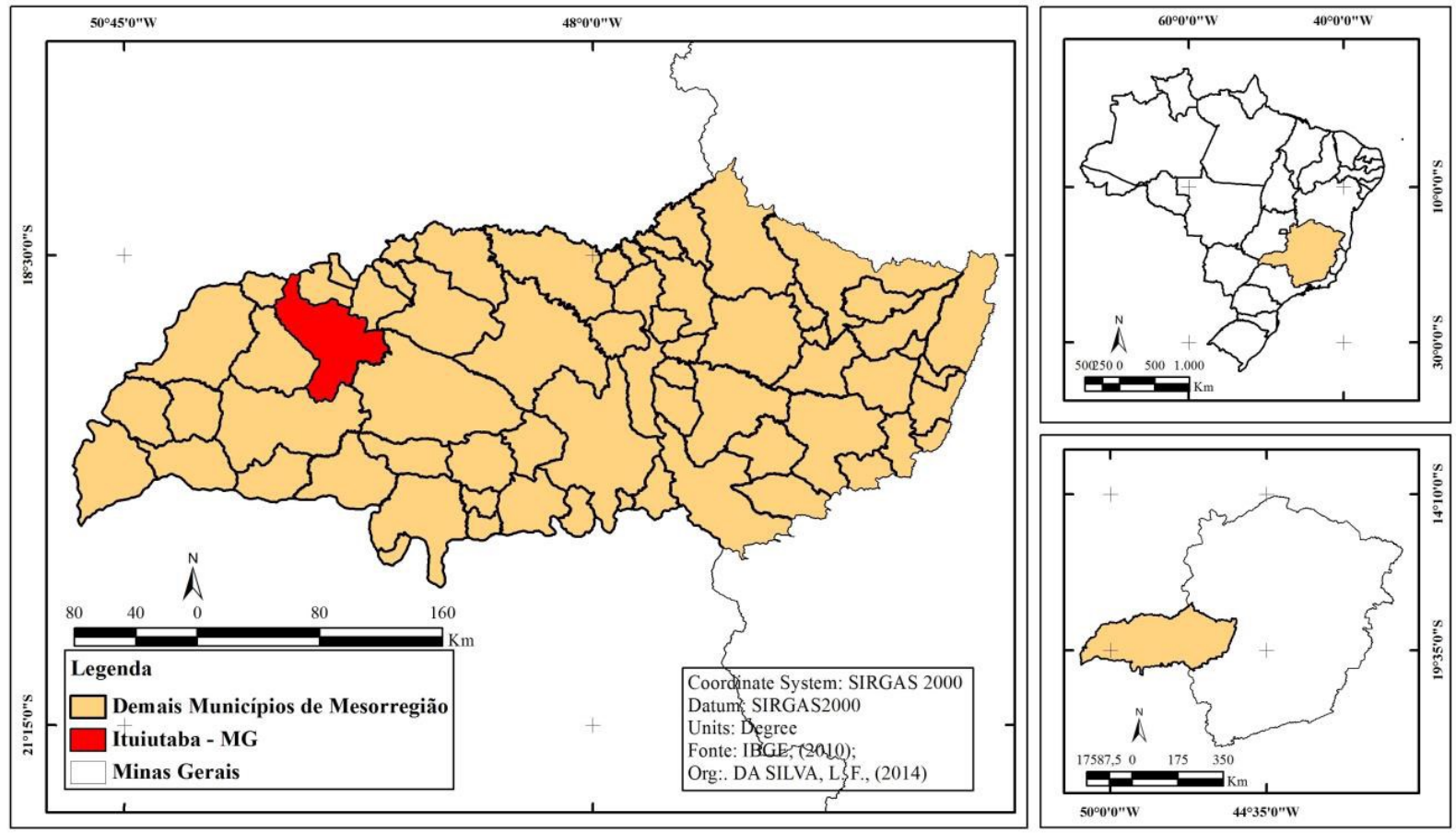

Fonte: IBGE (2010).

A população do município de Ituiutaba é de 102.690 segundo estimativas do IBGE 2014, sendo esta uma cidade que exerce importante papel em sua microrregião geográfica, principalmente pelas suas atividades econômicas e por seus equipamentos urbanos. Além disso, é importante considerar que Ituiutaba ganhou ainda mais importância no cenário regional na década de 1980 e 1990 quando recebeu empresas do setor comercial, agroindustrial e de serviços. Isso pode ser explicado pela dinamicidade da circulação de capital.

A partir do momento que a cidade ganha importância regional, e com os investimentos oriundos do governo federal, a malha urbana da cidade expande-se com o surgimento de vários loteamentos. Por isso, torna-se de fundamental importância os estudos referentes às dinâmicas ambientais, principalmente ligados a apropriação e ocupação do relevo e os impactos resultantes.

Foi pensando nestas problemáticas que escolheu-se como área de estudo o setor sul da cidade de Ituiutaba/MG (Figura 02), com o intuito de observar alguns desses impactos já mencionados, que estão relacionados à forma inadequada de apropriação e ocupação do relevo. 
Figura 02. Localização da área de estudo

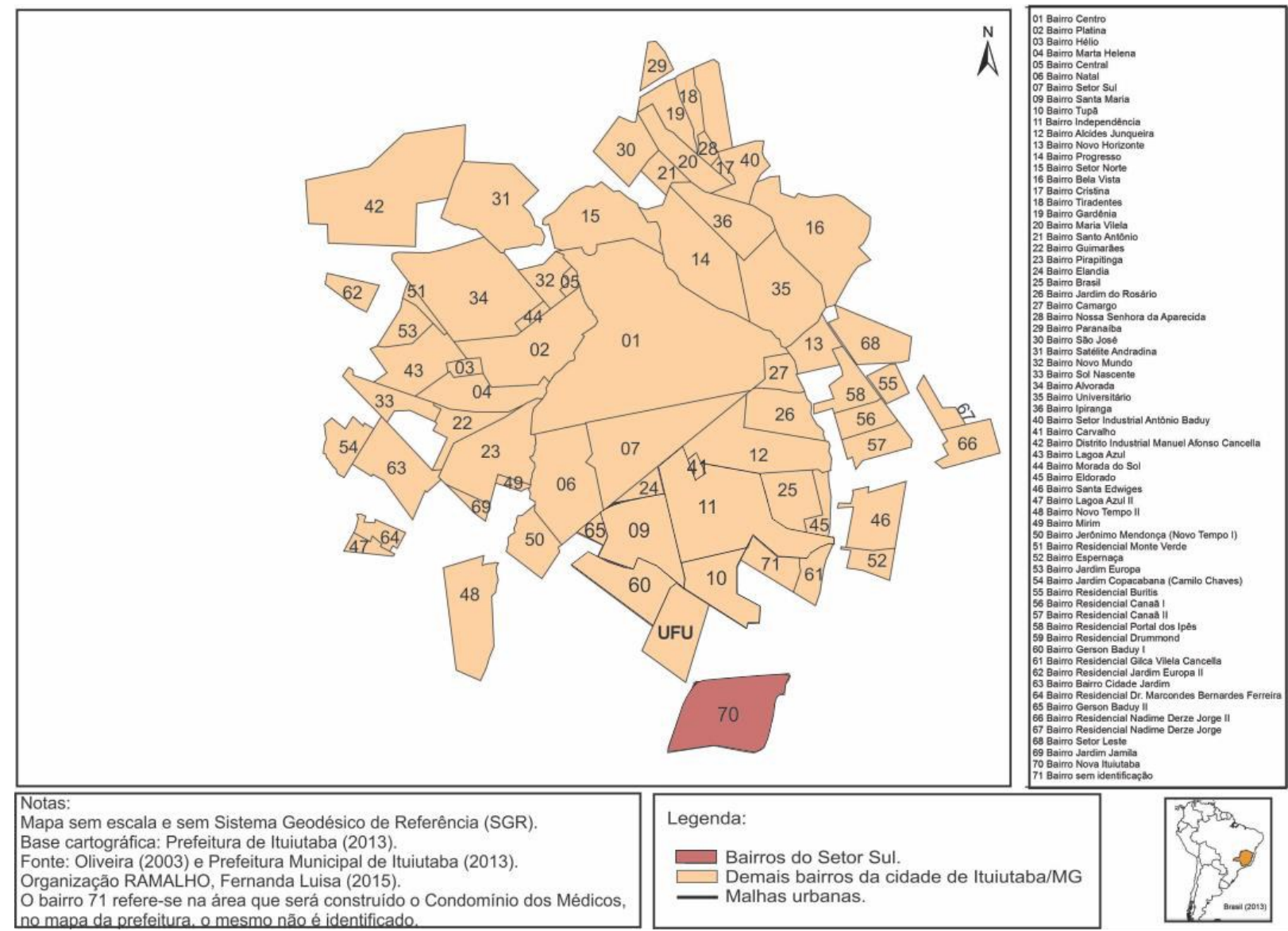

Fonte: OLIVEIRA 2013; Org.: RAMALHO, 2014

Para relacionar a apropriação e ocupação do relevo fez-se necessária a análise ambiental da cidade de Ituiutaba e dos bairros em estudo, proporcionando assim a análise integrada da paisagem (homem e natureza).

\section{OBJETIVOS}

O objetivo principal do trabalho foi identificar a ocupação dos compartimentos do relevo, com ênfase para as vertentes, e caracterizar os principais impactos ambientais oriundos da aceleração dos processos geomorfológicos nos loteamentos Nova Ituiutaba I, II do município de Ituiutaba - MG.

\section{METODOLOGIA}

Para alcançar os objetivos propostos foram adotados os seguintes procedimentos: 
1. Inicialmente foram feitos trabalhos de gabinete que envolve levantamento histórico e bibliográfico da ocupação de Ituiutaba, junto a órgãos públicos como Prefeitura Municipal, bibliotecas da Universidade Federal de Uberlândia e Municipal de Ituiutaba.

2. Para realizar a análise integrada da paisagem foram feitos mapeamentos, esboços e perfis longitudinais do relevo e do solo. O esboço geomorfológico foi elaborado a partir da análise de imagens de satélite disponíveis da área de estudo (Landsat, Google Earth), utilizando-se das chaves de interpretação tais como textura, estrutura, forma, padrão, baseado nas variações de tonalidade cinza e técnicas de geoprocessamento.

3. Foram feitos trabalhos de campo na área estudada para identificar os principais impactos e avaliar se os mapeamentos estão representando os aspectos mapeados.

\section{RESULTADOS}

De acordo com Martins e Costa (2012), a caracterização da morfoescultura situada no munícipio de Ituiutaba- MG contém feições geomorfológicas do tipo de relevo residuais, onde por sua vez, as áreas de maiores altitudes dessa forma de elevação se encontram em processo de dissecação, por outro lado, os locais mais rebaixados e retilíneos são dissecados pela drenagem.

Com o intuito de aprofundar os estudos sobre a morfologia do relevo traçou-se um perfil topográfico da área estudada, escolheu-se os seguintes pontos para observações de impactos ambientais (Figura 3): o ponto 1, localizado no topo da vertente; o ponto 2 no talude e o ponto 3 no fundo de vale. 
Figura 3: Pontos de coleta de solo e desenvolvimento do perfil topográfico

Fonte: Google Earth. Org: SILVA, J. V. F. (2015)

Os loteamentos habitacionais Nova Ituiutaba I e II foram implantados de forma que iniciaram-se as obras de terraplanagem nas áreas de domínio dos topos suavemente ondulados, expandindo-se pelo domínio das vertentes e por fim direcionando-se aos domínios dos fundos de vale. Essa intervenção provoca uma intensificação dos processos naturais, ou seja, aceleram-se os mesmos. Neste cenário, destacam-se os processos erosivos causados pela ação fluvial, no qual o runoff é intensificado e acelerado devido a declividade do terreno, bem como a impermeabilização das ruas.

Esses lotes quando edificados, a partir da construção de residências (Figura 04) e arruamentos (Figura 05) na sua maior parte impermeabilizados, contribui para o aumento do escoamento superficial e diminuindo a infiltração e a percolação no solo. Podendo levar a um rebaixamento do nível freático que abastece as nascentes dos córregos encontrados na área urbana e adjacências. Além de acelerar processo erosivo contribuindo para degradação desse ambiente (RAMALHO, 2015). 


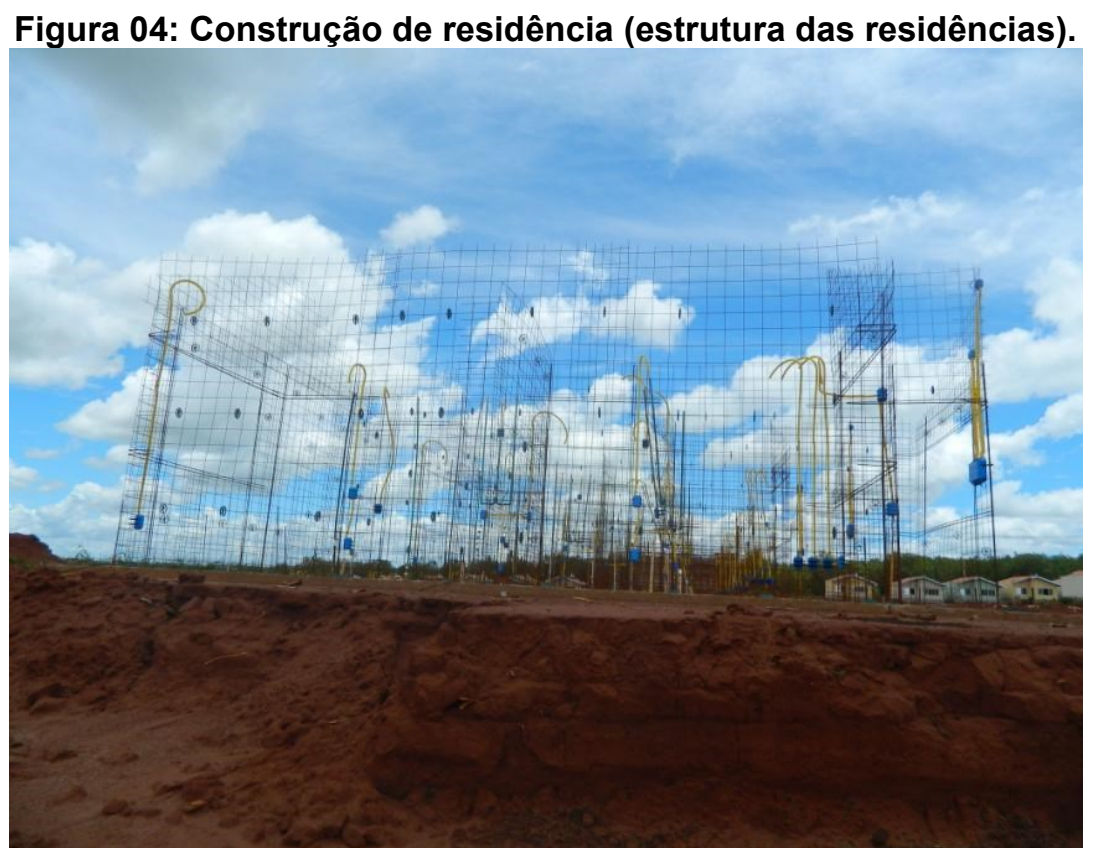

Fonte: autor: RAMALHO, F. L.; PEDRO MIYAZAKI, L. C. (Jul.2014)

Figura 05: Construção de arruamentos.

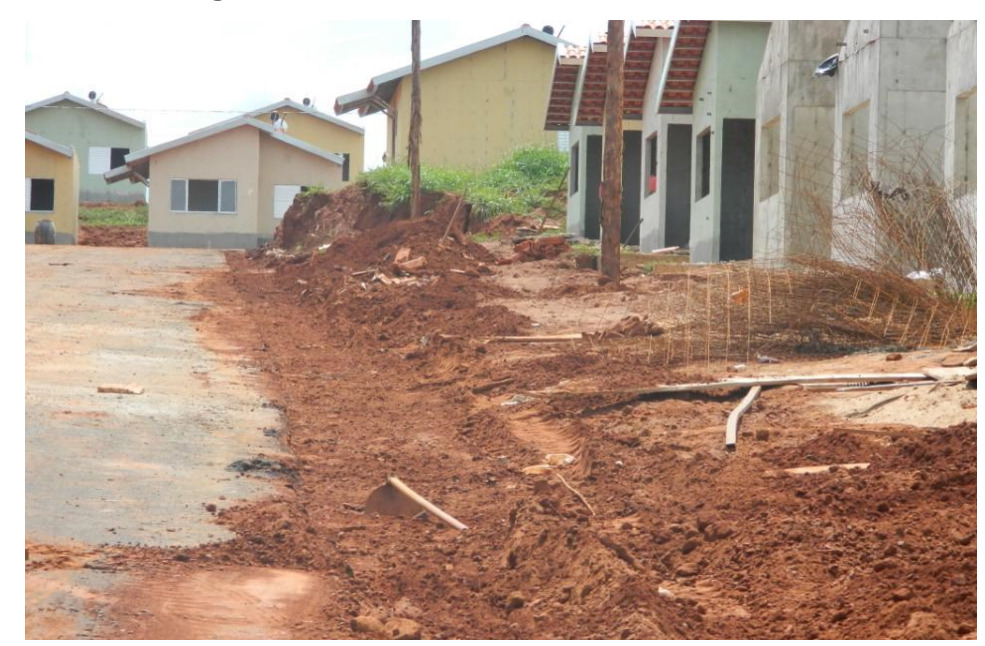

Fonte: autor: RAMALHO, F. L; PEDRO MIYAZAKI, L. C. (Jul.2014).

É fácil perceber que a ocupação das áreas de topo e das vertentes desencadeia alguns problemas ambientais urbanos, como por exemplo, erosões, assoreamento, movimento de massa entre outros (Figura 06). Por isso, antes de ocupar determinado tipo de relevo deve-se levar em consideração as características naturais e analisar sua potencialidade, bem como suas fragilidades, de modo a evitar impactos no meio ambiente. Segundo Ramalho (2015) esses impactos são percebidos nos bairros através das erosões decorrentes do escoamento superficial, 
dos depósitos tecnogênicos (Figura 07) e do assoreamento do curso d'água (Figura 08).

Figura 06: Erosão e movimentos de massa

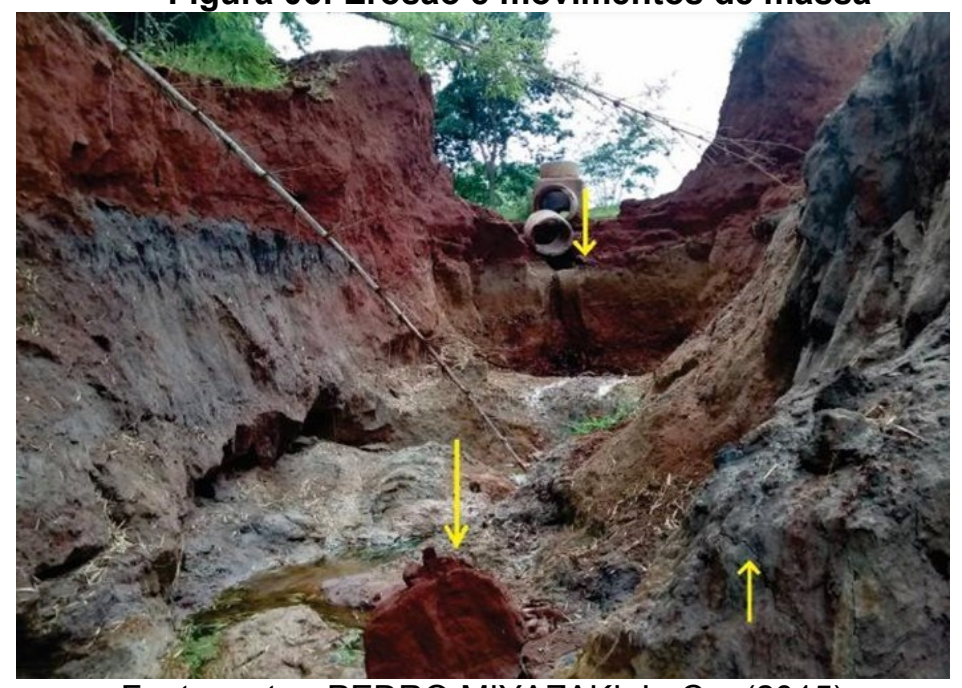

Fonte: autor: PEDRO MIYAZAKI, L. C.. (2015)

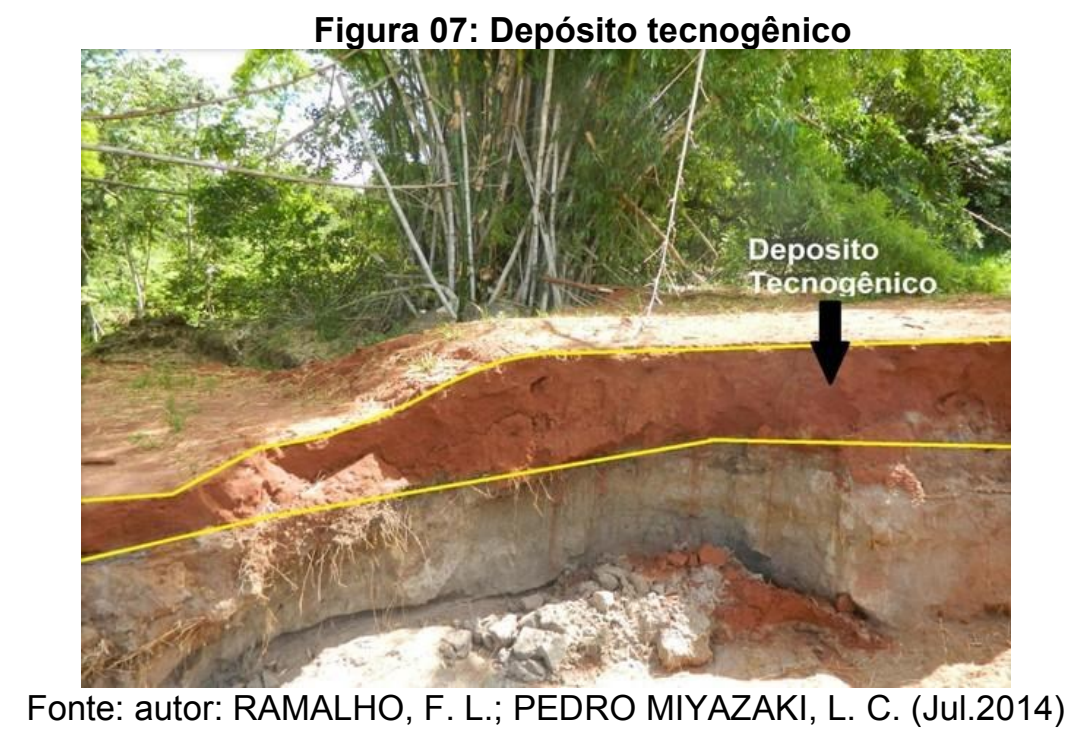

Pedro (2008) ressalta que os depósitos tecnogênicos são formações decorrentes da acumulação de materiais úrbicos, de resíduos sólidos domésticos em alguns compartimentos do relevo, as planícies tecnogênicas são exemplos dessas formas de relevo, sendo áreas planas formadas pelo acúmulo de sedimentos e outros tipos de materiais.

O assoreamento é um processo geomórfico de deposição de sedimentos, ex: fluvial, eólico e marinho (GUERRA; GUERRA, 2008). Para Suertegaray, et al (2008), 
o mesmo consiste no processo de acumulação de material detrítico, oriundo de processos erosivos, quando o curso d'água não tem condições de transportar a carga sedimentar. Esse processo é responsável pela formação de depósitos de barra (Figura 08), tanto no canal como nas margens de córregos (RAMALHO, 2015).

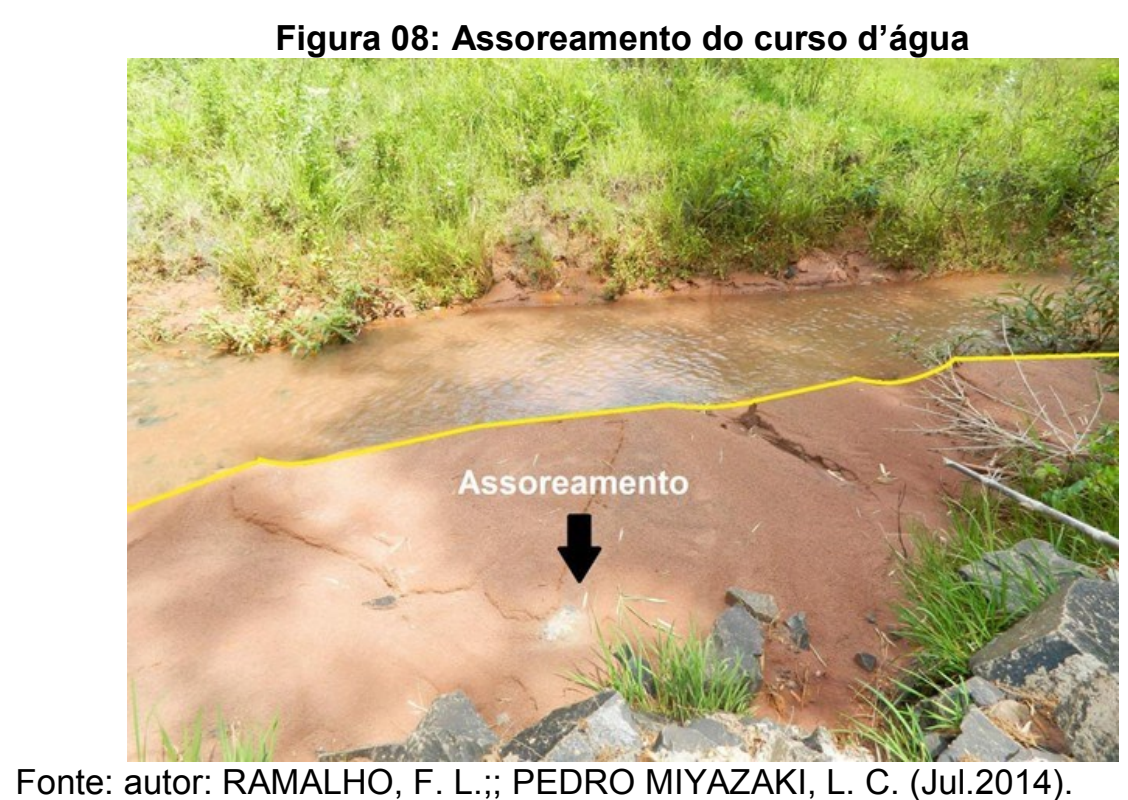

Esses assoreamentos são decorrentes do escoamento superficial que ocorre nas encostas durante um evento chuvoso, quando a capacidade de armazenamento de água no solo é saturada (RAMALHO, 2015). Para Suertegaray, et al (2008), esse escoamento pode ser areolar, quando a água escoa regularmente sobre a superfície, dividindo-se em escoamento difuso e laminar, ou pode ser linear, concentrando-se em canais.

Conforme Ramalho (2015) na área de estudo o escoamento linear (concentrado) estava presente em vários pontos dos bairros (Figura 09). Suertegaray, et al (2008) ressalta que esse escoamento ocorre quando as águas se concentram possuindo maior competência erosiva e fixando leito, deixando marcas na sua superfície topográfica formando ravinas e voçorocas (Figura 10). 
Figura 09: Escoamento Concentrado

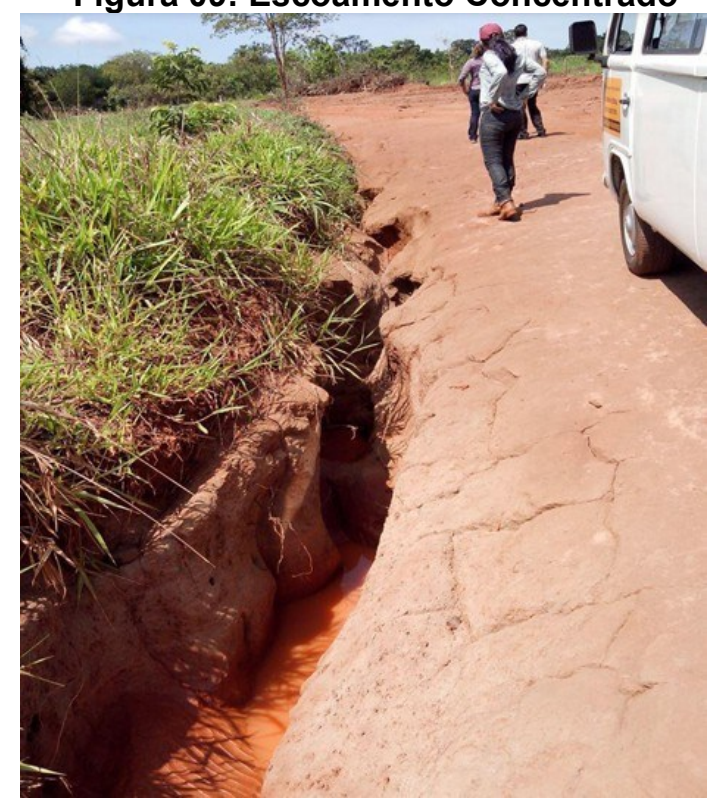

Fonte: autor: RAMALHO, F. L.; PEDRO MIYAZAKI, L. C. (Dez.2014).

Figura 10: Voçoroca entre os bairros Nova Ituiutaba I e II

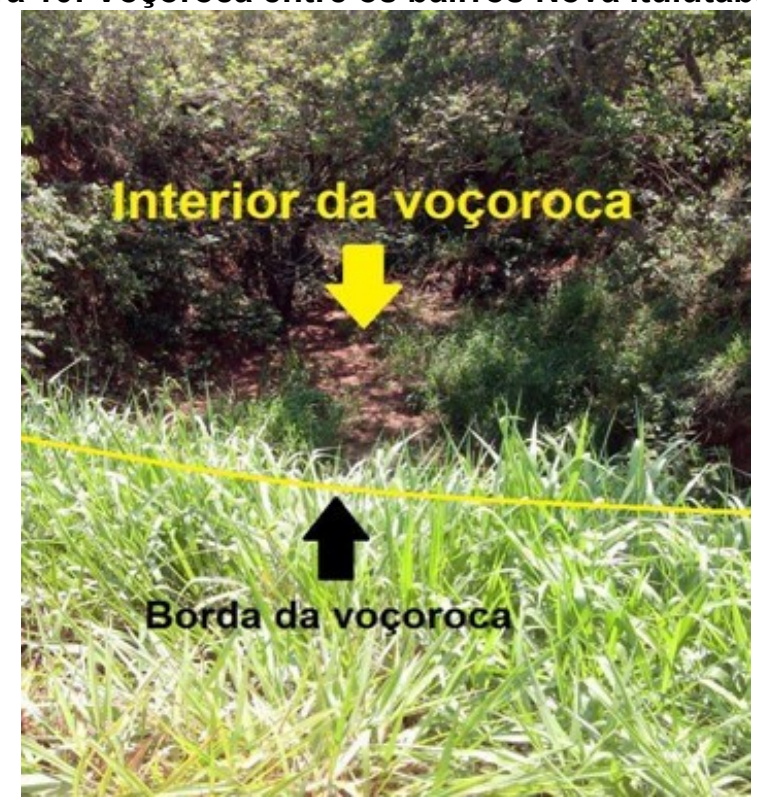

Fonte: autor: RAMALHO, F. L.; PEDRO MIYAZAKI, L. C. (Dez.2014).

As voçorocas segundo Suertegaray, et al (2008), podem ser originadas pelo aprofundamento e alargamento de ravinas, ou por erosão causada pelo escoamento subsuperficial, o qual dá origem a dutos (pipes). São relativamente permanentes nas encostas, têm paredes laterais íngremes, em geral fundo chato, ocorrendo fluxo de água no seu interior durante períodos chuvosos (RAMALHO, 2015). Possuem uma feição erosiva acelerada e de instabilidade nas paisagens. Para Guerra; Guerra 
(2008) voçoroca é uma escavação ou rasgão do solo ou de rocha decomposta, ocasionado pela erosão do lençol de escoamento superficial, podendo também ser formadas por escoamento subsuperficial.

$\mathrm{Na}$ figura 09 podemos observar a voçoroca que há entre os bairros estudados. Pode-se observar a presença de vegetação em todo o seu interior, a qual contribui para sua estabilização. Contudo, durante a construção dos novos loteamentos, no processo de preparação do solo para construção das residências, a empresa responsável, de forma irregular, terraplanou a cabeceira da voçoroca como pode ser observado na figura 11 (RAMALHO, 2015).

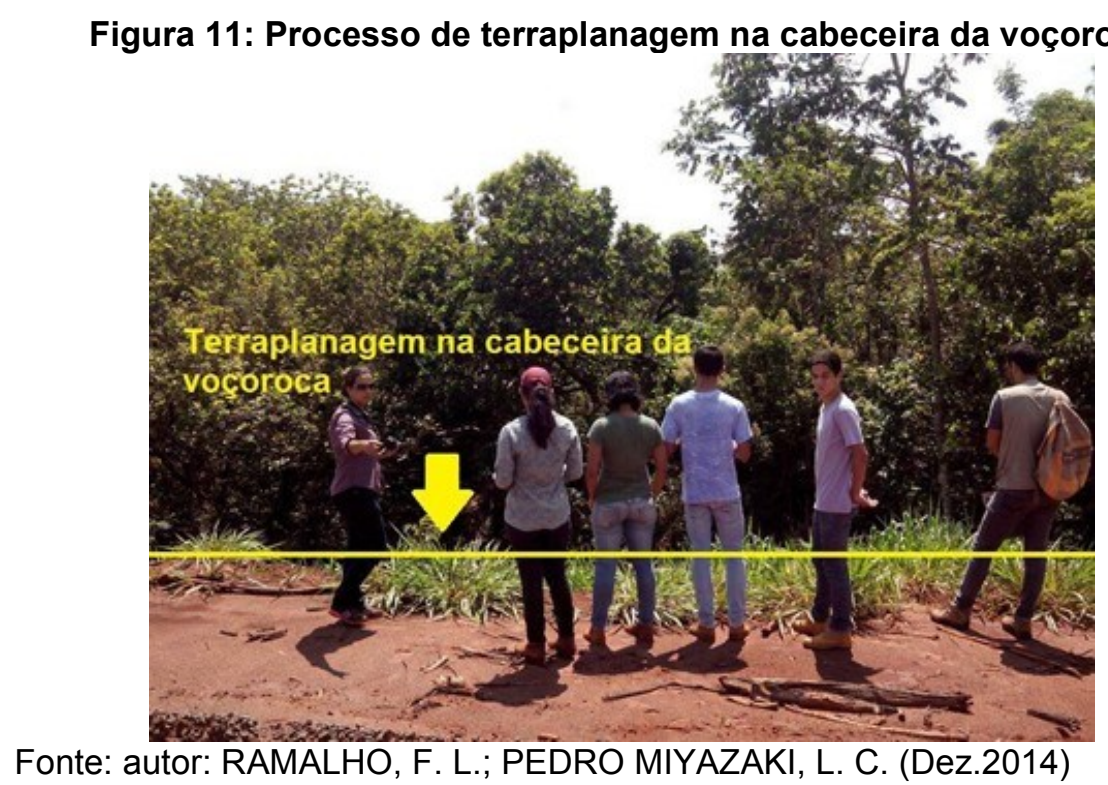

Após a retirada da vegetação local foi feito um processo de terraplanagem, o qual prepara o solo para construção de loteamentos. Esse processo faz com que o solo fique e mais vulnerável às feições erosivas. No caso da cabeceira da voçoroca na área de estudo, futuramente podem ocorrer solapamentos da borda, podendo atingir as casas que estão a sua proximidade, estando este diretamente relacionado a remoção de material da base de uma vertente (RAMALHO, 2015).

Antes da instalação dos conjuntos habitacionais, a área em questão era coberta por vegetação natural que foi derrubada para ceder lugar à massa de concreto. A obra foi estruturada e aprovada pela prefeitura municipal em construção 
do programa "Minha Casa Minha Vida", para conceber a população de baixa renda o sonho de possuir sua casa própria.

\section{CONCLUSÃO}

Nos bairros Nova Ituiutaba I e II foram observados vários impactos ambientais notados principalmente nas áreas de fundo de vale, local em que fora depositado todo o material oriundo da construção civil.

A obra destinada aos grupos sociais menos privilegiado demonstra alguns fatores que contribuem nos processos erosivos e intensificam os danos ao meio ambiente, como por exemplo: a impermeabilização do solo e a falta de estrutura necessária para o escoamento da água da chuva (no local não há bueiros/boca de lobo).

De acordo com (CASSETI, 1995) a alteração do local, retirada da cobertura vegetal, dificultará a infiltração da água no solo, proporcionando uma desagregação mecânica deste, tendo como consequência, os processos de ravinamentos, voçorocamentos e até mesmo deslizamento de terras. Para (MARTINS; COSTA, 2012) "os processos erosivos são um dos problemas ambientais mais significativos na área urbana e rural de Ituiutaba".

Essa forma de ocupação das vertentes transformam e esculturam o relevo, por meio da aceleração dos processos geomorfológicos e na maioria das vezes contribuem para a formação de paisagens degradadas, como notados anteriormente.

Além desses, outro fator que contribui para o aumento dos processos erosivos e para a contaminação do solo no local são os descartes indevidos de resíduos (plástico, vidro, alumínio, etc.), os quais foram encontrados às margens do córrego São José, e que decorrem, provavelmente, de um processo de urbanização realizado de forma irregular e sem planejamento.

Dessa forma, pode-se notar durante as pesquisas em campo e levantamentos de dados que são vários os fatores contribuintes para o aceleramento dos processos erosivos que ocorrem no local, sendo o principal a instalação dos loteamentos habitacionais Nova Ituiutaba I e II, que, desprovidos de planejamento, causam danos tanto ao meio ambiente quanto a população. 


\section{REFERÊNCIAS}

AMARAL, D. A. Noções de Conservação do Solo. 2. ed. Editora Nobel, 1984.

CASSETI, V. Ambiente e apropriação do relevo. São Paulo: Editora Contexto, 1991.

CASSETI, Valter. Geomorfologia. [S.I.]: [2005]. Disponível em: <http://www.funape.org.br/geomorfologia/>. Acesso em: 19 de jan. de 2014.

CASSETI, V. Proposta metodológica para elaboração de carta de risco. Boletim Goiano de Geografia, Goiânia, v.15, n.1, p. 81 - 88, jan./dez., 1995.

CORRÊA, R. L. O espaço urbano. 4ª edição, 2ª reimpressão. São Paulo: Editora Ática, 2000.

GUERRA, A. J. T. \& CUNHA, S.B.. Geomorfologia e Meio Ambiente. Bertrand, Rio de Janeiro, 1996.

IBGE: Cidades. Disponível em: <http://www.ibge.gov.br/cidadesat/painel/painel.php ?codmun=313420\#>. Acessado em 06 de maio de 2013.

GUERRA, A.T.G. \& GUERRA, A. J. T. Novo Dicionário Geológico-Geomorfológico - 6 ed. - Rio de Janeiro: Bertrand Brasil, 2008.

NASCIMENTO, P. A. G. Ituiutaba (MG): análise da sua área de influência a partir da atuação de órgãos públicos estaduais e federais no ano de 2010. Anais do XVI Encontro Nacional dos Geógrafos: Crise, práxis e autonomia: espaços de resistência e de esperanças. 2010.

MARTINS, F.; COSTA, R. Compartimentação Morfológica do Município de Ituiutaba, Estado de Minas Gerais, Brasil. In: Simpósio Nacional de Geomorfologia, IX, 2012, Rio de Janeiro/RJ. Anais Geomorfologia e Eventos Catastróficos: passado, presente e futuro. Rio de Janeiro: UFRJ, 2012. Disponível em: < http://www.sinageo.org.br/2012/trabalhos/8/8-122-75.html> Acesso em: 15 de abril de 2015.

OLIVEIRA, H. C. M.. Urbanização e cidades: análises da microrregião de Ituiutaba (MG). 2013. 431 f. Tese (Doutorado) - Universidade Federal de Uberlândia, Uberlândia, 2013.

PEDRO, L. C. Ambiente e apropriação dos compartimentos geomorfológicos do Conjunto Habitacional Jardim Humberto Salvador e Condomínio Fechado Damha. Dissertação (Mestrado em Geografia). Universidade Estadual Paulista, Faculdade de Ciência e Tecnologia. Presidente Prudente, 2008.

RAMALHO, F. L. Impactos ambientais oriundos do processo de ocupação do relevo nos bairros Nova Ituiutaba I e Nova Ituiutaba II - Ituiutaba/MG. Relatório Parcial de Iniciação Científica/ PIBIC/CNPq. Universidade Federal de Uberlândia, Campus Pontal. Ituiutaba/MG, 2015;

SUERTEGARAY, D. M. A. Geografia física e geomorfologia: uma (re) leitura. ljuí: Ed. Unijuí, 2002.

SUERTEGARAY, Dirce Maria Antunes e NUNES, João Osvaldo Rodrigues. A natureza da geografia física na geografia, In: TERRA LIVRE 17: Paradigmas da Geografia. Parte II. São Paulo: AGB, 2001.

SUERTEGARAY, D. M. A (Organizadora). Terra: feições ilustradas - 3 ed. - Porto Alegre: Editora da UFRGS, 2008. P.264. 